\title{
Nucleolus Organising Chromosomes in Brassica and Their Bearing on the Phylogeny of the Genus
}

\author{
T. Kamala \\ Andhra University, Waltair, India
}

Received February 18, 1975

Gates (1942) recognised a numerical correspondence in the nucleoli and satellites and their bearing on determining the ploidy of the taxon. Although later workers like De Wet (1953) and Stebbins (1964) did not report such a correspondence in the materials studied by them, in Brassica however during the course of the investigation made here on the pachytene chromosomes in the genomes ' $a$ ', ' $b$ ' and ' $c$ ' and their hybrids, a numerical correspondence in the number of nucleolus organisers has been observed in the different species studied here and the details are presented in this paper.

Materials and methods

The following species of Brassica and Raphanus and their hybrids are included in this investigation.

$B$. campestris var. oleifera $(\mathrm{n}=10), B$. pekinensis $(\mathrm{n}=10), B$. juncea var. gracilis $(\mathrm{n}=18)$

$B$. napus var. oleifera $(\mathrm{n}=19)$, Raphanus sativus $(\mathrm{n}=9)$ and $R$. raphanistrum $(\mathrm{n}=9)$.

$B$. napus var. oleifera $(\mathrm{n}=19) \times B$. campestris var. oleifera $(\mathrm{n}=10)$,

$$
\mathrm{H}_{1}, \mathrm{~F}_{1}(2 \mathrm{n}=29) \text {, }
$$

$B$. campestris var. oleifera $(\mathrm{n}=10) \times B$. napus var. oleifera $(\mathrm{n}=19)$,

$$
\mathrm{H}_{2}, \mathrm{~F}_{1}(2 \mathrm{n}=29) \text {, }
$$

$B$ napus var. oleifera $(\mathrm{n}=19) \times B$. chinensis var. communis $(\mathrm{n}=10)$,

$$
\mathrm{H}_{3}, \mathrm{~F}_{1}(2 \mathrm{n}=29) \text {, }
$$

$B$. juncea var. gracilis $(\mathrm{n}=18) \times R$, raphanistrum $(\mathrm{n}=9)$,

$$
\mathrm{H}_{4}, \mathrm{~F}_{1}(2 \mathrm{n}=27) \text {, }
$$

$B$. napus va1. oleifera $(\mathrm{n}=19) \times R$. raphanistrum $(\mathrm{n}=9)$,

$$
\mathrm{H}_{5}, \mathrm{~F}_{1}(2 \mathrm{n}=28) \text {. }
$$

Flower buds for pachytene chromosome studies were fixed in a fresh mixture of 1:3 acetic acid-absolute alcohol at 10 a.m. Chromosomes for pachytene studies were stained with $1 \%$ acetocarmine with ferric chloride as mordant. Camera lucida drawings were made from fresh preparations at bench level using $15 \mathrm{x} \times$ oel. Photographs were made from fresh preparations. Chromosomes were measured with a graduated twine thread.

\section{Results}

In the 4 diploid Brassica species studied here the species $B$. campestris var. oleifera $(\mathrm{n}=10)$ and $B$. pekinensis $(\mathrm{n}=10)$ contained each two morphologically 
distinct nucleolus organising chromosomes designated as types $A_{1}$ and $A_{2}$ (Fig. 1 and 2 ) in the haploid set while $B$. juncea var. gracilis $(\mathrm{n}=18)$ and $B$. napus var. oleifera $(n=19)$ contained 4 nucleolus organising chromosomes each in their haploid sets. Two of these in the latter two species belonged to the ' $a$ ' genome and the other two to the ' $b$ ' and ' $c$ ' genomes respectively (Figs. 3 and 4). These observations agree well those of Röbbelen (1960). Sikka (1940) observed a numerical correspondence in the number of nucleoli and satellite chromosomes at somatic metaphase in the different Brassica species studied by him. However the details observed here differ from the report of Sikka (1940) regarding the number of nucleolus organising chromosomes in the different species and from that of Röbbelen (1960) regarding the morphology of one of the nucleolus organisers and the same are presented here.

1. Sikka (1940) observed two nucleoli and two satellitic chromosomes in each of the three species $B$. oleracea $(\mathrm{n}=9), B$. campestris $(\mathrm{n}=10)$ and $B$. napus

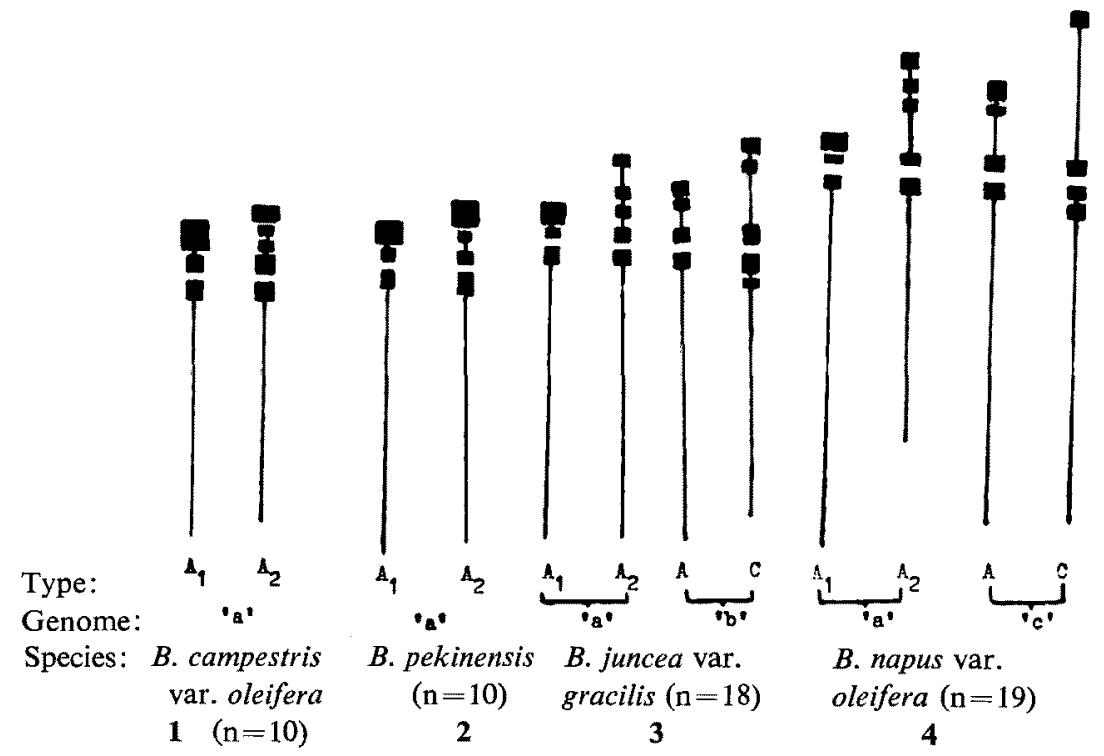

Figs. 1-4. Type, genome and species of nucleolus organizing chromosomes.

$(\mathrm{n}=19)$. In the present investigation of $B$. campestris var. oleifera $(\mathrm{n}=10)$ and $B$. pekinensis $(\mathrm{n}=10)$ both with the 'a' genome two nucleolus organising chromosomes were seen. In $B$. napus var. oleifera $(n=19) 4$ nucleolus organisers were seen two of which belong to the two of the ' $a$ ' genome, whereas the other two belong to the chromosomes of the ' $c$ ' genome.

2. In $B$. juncea Sikka (1940) found three pairs of satellitic chromosomes and 6 nucleoli, while in the present study in $B$. juncea var. gracilis $(n=18)$ four nucleolus organising chromosomes were seen at pachytene, two of which resemble the two nucleolus organising chromosomes of $B$. campestris var. oleifera and the remaining two belong to the ' $b$ ' genome of $B$. nigra.

Although these observations largely agree with those of Röbbelen (1960) they differ from his in respect of the nucleolus organising chromosome 10 of $B$. napus var. oleifera which corresponds to the second nucleolus organising chromosome of 
the ' $c$ ' genome. This chromosome possesses a terminal well defined heterochromatic satellite in the complement of B. napus var. oleifera $(n=19)$ (Fig. 4) whereas Röbbelen (1960) observed in $B$. oleracea varieties the distal euchromatic portion of the chromosome serving as a satellite.

\section{Discussion}

The two nucleolus organisers in each of these three genomes ' $a$ ', ' $b$ ' and ' $c$ ' did not pair with each other in the three interspecific and two intergeneric hybrids

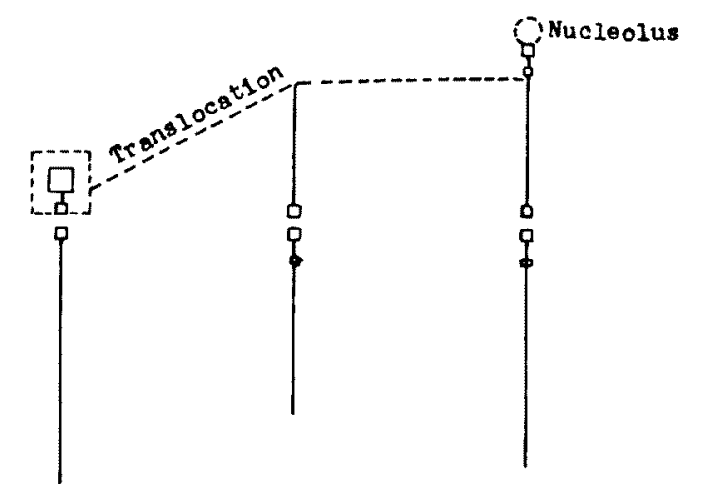

\begin{tabular}{|c|c|c|}
\hline $\begin{array}{l}\text { Nucleous } \\
\text { organising } \\
\text { chromosome } \\
\text { type } \mathrm{A}_{2} \text { of } \\
\text { 'a' genome }\end{array}$ & $\begin{array}{l}\text { Chromosome } \\
\text { type } C \text { of } \\
\text { ' } a \text { ' and 'c' } \\
\text { genomes }\end{array}$ & $\begin{array}{l}\text { Nucleolus } \\
\text { organising } \\
\text { chromosome } \\
\text { type C of } \\
\text { ' } b \text { ' and 'c' } \\
\text { genomes }\end{array}$ \\
\hline
\end{tabular}

Fig. 5. Schematic diagram suggesting the probable origin of nucleolus organising chromosome in the ' $b$ ' and ' $c$ ' genomes from the nucleolus organising chromosome of ' $a$ ' genome. studied here. Therefore, it is suggested that they were derived from two distinct parents.

On the assumption that the number of nucleoli or satellites is an index of the ploidy of a taxon (Gates 1942) the three genomes ' $a$ ', 'b' and 'c' might be considered as allotetraploids and the species $B$. juncea var. gracilis $(\mathrm{n}=18)$ and $B$. napus var. oleifera $(\mathrm{n}=19)$ as allo-octoploid hybrids having arisen due to natural hybridisation of the genomes ' $a$ ', 'b' and ' $c$ '. The number of nucleoli however did not show any correspondence with those of the satellitic chromosomes. Such a lack of correspondence in the number of nucleoli has also been reported in Danthonia polyploids (De Wet 1953).

The discrepancy between the present observations and those of Sikka (1940) and of Röbbelen (1960) may be ascribed to the fact that the terminal heterochromatic satellite in the materials studied by them might have been lost due to mutation in the course of evolution of the species as has been suggested by Gates (1942) in the several materials studied by him. Such a possibility has also been suggested by Sikka (1940) in Brassica and De Wet (1953) in Danthonia polyploids. Navaschin $(1926,1934)$ applied the term amphiplasty to such a phenomenon observed by him in Crepis. Ramanujam (1937) found in rice varieties the loss of one pair of nucleoli and also the deletion of not only the satellite and thread but also of the nucleolus organizer at the end of the chromosome. Such a loss has also been reported by Jacob (1940) in Cassia sps. Gates (1942) suggested a probability that a satellite can be lost also by a gradual diminution until it is below the limits of visibility and that further change in the same direction will lead to its functional and structural diminution.

In polyploids although the terminal nucleolus organiser or the satellite were 
lost that would not affect the cytological balance of the plant very severely and the plant would continue to survive. Since the genus Brassica is ancient and its exact origin is not yet determined the genus allows for enough time for such a process to take place as has also been interpreted in the case of Danthonia (De Wet 1953).

Another possibility is there that the nucleolus organiser chromosome 8 (type $A_{2}$ ) which is having a short arm so short enough at pachytene itself that there is the likelihood of this being not clearly visible in the somatic chromosomes, since the chromosomes of Brassica at somatic metaphase are so very small that neither the centromere nor the nucleolus organiser on it could be located with any confidence. It appears from our studies made here that this chromosome 8 is characteristic or is a regular member of the forms with ' $a$ ' genome alone and so it is equally likely that in all the forms with ' $\mathrm{a}$ ' genome with $2 \mathrm{n}=20$ such as $B$. rapa $\mathrm{L}$., B. campestris L., B. trilocularis L., and $B$. tourneforti studied by Sikka (1940) the short arm of this may not be easily discernible at somatic metaphase.

Since the number of species investigated here is very small we could not demonstrate the exact origin of any variety or species or the loss or diminution of the size of the satellite. Therefore it is suggested here as a possibility apparent from the observations made here. The two nucleolus organising chromosomes of the ' $a$ ' genome are referred here as types $A_{1}$ and $A_{2}$ and those of the ' $b$ ' and ' $c$ ' genomes as the types $A$ and $C$ as already stated (Venkateswarlu and Kamala 1971). The chromosomes of the type $A_{1}$ of the ' $a$ ' genome and the type $A$ of the ' $b$ ' and ' $c$ ' genomes are found to be morphologically similar except for the number of intercalary chromosmeres between the terminal satellite and the proximal heterochromatic segment on the short arm (Figs. 1-4). But the chromosomes of the type $\mathrm{A}_{2}$ of the ' $a$ ' genome and type $C$ of the ' $b$ ' and ' $c$ ' genomes are quite different in their morphology. The chromosomes of the type $C$ of the ' $b$ ' and ' $c$ ' genomes seem to be more closely related morphologically with chromosome type $C$ of the ' $a$ ' genome. Although the chromosome type $\mathrm{A}_{2}$ is present in the ' $b$ ' and 'c' genomes of Brassica such a type of chromosome is also seen in some other genera of Cruciferae like Diplotaxis muralis, Erysimum cheiranthoides, and Raphanus sps. which have been examined here for comparison during this study. It is obvious that this chromosome forms one of the basic types of the haploid chromosomal complement of atleast some of the Cruciferae.

It appears from the observations of the pairing of chromosomes in the interspecific and intergeneric hybrids studied here that the nucleolar chromosome in the ' $b$ ' and ' $c$ ' genomes might have originated due to a non-homologous translocation between a nucleolar and a non-nuclear chromosome in the original hybrid which gave rise to the ' $b$ ' and ' $c$ ' genomes. The second nucleolus organising chromosome of the type $C$ in the ' $b$ ' and ' $c$ ' genomes probably resulted from a non-homologous and unequal translocation involving the terminal portion of the $\mathrm{C}$ type of chromosome (i.e. a non-nuclear type) and the short arm of the chromosome type $\mathrm{A}_{2}$ seen in the 'a' genome (Fig. 5). Such a type of non-homologous translaocation has been recorded in Triticum macha (Bhaduri and Ghosh 1955). They found an extra pair of nucleolar chromosomes with supernumerary constriction being separated by a small chromosome segment. This has been interpreted by them as derived 
through a translocation between two non-homologous chromosomes. Although no translocation configurations could be observed there in Brassica species involving the above referred chromosomes, the observation of anaphase bridges in the Brassica species by Sikka (1940) supports our above conclusion. Sikka (1940) also suggested that translocations may play a role in the phylogeny of Brassica.

The number of nucleoli however does not show any correspondence with those of the satellitic chromosomes. Such a lack of correspondence in the number of nucleoli has also been reported in Danthonia polyploids (De Wet 1953).

Although Gates (1942) indicated that the number of nucleoli and the nucleolar regions should proportionally increase in the polyploids he stated that many polyploids are characterised by two pairs of nucleoli. Bergman (1935) showed in Leontodon incanus and L. asperrimus two chromosome pairs bearing satellites and producing two pairs of nucleoli. Stebbins (1964) indicated that many polyploids are known that never produce more than two nucleoli. In the four diploid Brassica species studied here only two nucleoli could be seen. Therefore in Brassica although the number of nucleolar chromosomes does not seem to deny the theory of Gates (1942) the number of nucleoli could not help in deciding the degree of ploidy of the complement.

\section{Summary}

A numerical correspondence is seen in the number of nucleolus organising chromosomes in the 4 diploid Brassica species referred in the text. Based on the numerical correspondence the allopolyploid nature of not only of $B$. juncea var. gracilis $(\mathrm{n}=18)$ and $B$. napus var. oleifera $(\mathrm{n}=19)$ but also of the three genomes ' $a$ ', ' $b$ ' and ' $c$ ' has been suggested. The probable origin of the nucleolus organising chromosome of ' $b$ ' and ' $c$ ' genomes from that of ' $a$ ' genome through a reciprocal translocation has also been suggested.

\section{Acknowledgements}

I am grateful to Prof. J. Venkateswarlu for guidance, and for providing facilities during the conduct of this work.

\section{References}

Bergman, B. 1935. Zytologische Studien über die Fortpflanzung bei den Gattungen Leontodon und Picris. Svensk. Bot. Eidskr. 29: 155-301.

Bhaduri, P. N. and Ghosh, P. N. 1955. SAT-chromosome of Triticum macha. A unique feature among Triticum species. Cytologia $20: 148-149$.

Jacob, K. T. 1940b. Chromosome numbers and the relationship between satellites and nucleoli in Cassia and certain other Leguminoseae. Ann. Bot. n.s. 4: 201-266.

Navaschin, M. 1926. Variabilität des Zellkerns bei Crepis-Arten in Bezug auf die Artbildung. Z. Zellforsch. 4: 171-215.

- 1934. Chromosome alterations caused by hybridisation and their bearing upon genetic problems. Cytologia 5: 169-203.

Oka, H. and Kao, C. 1956. Variation in nucleolar number among varieties of cultivated rice. 
Cytologia 21: $44-49$.

Ramanujam, S. 1937a. Cytological behaviour of an autotriploid in rice (Oryza sativa sativa L.). J. Genet. 35: 183-221.

Röbbelen, G. H. 1960. Beiträge zur Analyse des Brassica Genoms. Chromosoma (Berl.) 11: 205-228.

Sikka, S. M. 1940. Cytogenetics of Brassica hybrids and species. J. Genet. 40: 441-509.

Stebbins, G. L. 1964. Variation and Evolution in Plants. Columbia Biological Series.

Venkateswarlu, J. and Kamala, T. 1971. Pachytene chromosome complements and genome analysis in Brassica. J.I.B.S. 50A : 442-447.

Wet, J.M.J.De, 1953. Nucleoli numbers in Danthonia polyploids. Cytologia 18: 229-234. 